\title{
Article \\ THC and CBD Fingerprinting of an Elite Cannabis Collection from Iran: Quantifying Diversity to Underpin Future Cannabis Breeding
}

\author{
Mahboubeh Mostafaei Dehnavi ${ }^{1}$, Ali Ebadi ${ }^{1}$, Afshin Peirovi ${ }^{2}$, Gail Taylor ${ }^{3, *}$ and Seyed Alireza Salami ${ }^{1,4, *}$ \\ 1 Department of Horticultural Sciences, Faculty of Engineering and Agricultural Science, University of Tehran, \\ Karaj 31587-77871, Iran; mmostafaei@ut.ac.ir (M.M.D.); aebadi@ut.ac.ir (A.E.) \\ 2 CIAN Diagnostics, 5330 Spectrum Drive, Suite I, Frederick, MD 21703, USA; afshin700@yahoo.com \\ 3 Department of Plant Sciences, University of California Davis, Davis, CA 95616, USA \\ 4 Industrial and Medical Cannabis Research Institute (IMCRI), Tehran 14176-14411, Iran \\ * Correspondence: gtaylor@ucdavis.edu (G.T.); asalami@ut.ac.ir (S.A.S.); Tel.: +1-530-752-9165 (G.T.); \\ +98-2632248721 (S.A.S.)
}

check for updates

Citation: Mostafaei Dehnavi, M.; Ebadi, A.; Peirovi, A.; Taylor, G.; Salami, S.A. THC and CBD

Fingerprinting of an Elite Cannabis Collection from Iran: Quantifying Diversity to Underpin Future Cannabis Breeding. Plants 2022, 11, 129. https://doi.org/10.3390/ plants11010129

Academic Editors:

Domenico Trombetta,

Sebastian Granica and

Antonella Smeriglio

Received: 1 November 2021

Accepted: 16 December 2021

Published: 4 January 2022

Publisher's Note: MDPI stays neutral with regard to jurisdictional claims in published maps and institutional affiliations.

Copyright: (c) 2021 by the authors Licensee MDPI, Basel, Switzerland. This article is an open access article distributed under the terms and conditions of the Creative Commons Attribution (CC BY) license (https:// creativecommons.org/licenses/by/ $4.0 /)$.

\begin{abstract}
Cannabis (Cannabis sativa L.) has a rich history of human use, and the therapeutic importance of compounds produced by this species is recognized by the medical community. The active constituents of cannabis, collectively called cannabinoids, encompass hundreds of distinct molecules, the most well-characterized of which are tetrahydrocannabinol (THC) and cannabidiol (CBD), which have been used for centuries as recreational drugs and medicinal agents. As a first step to establish a cannabis breeding program, we initiated this study to describe the HPLC-measured quantity of THC and CBD biochemistry profiles of 161 feral pistillate cannabis plants from 20 geographical regions of Iran. Our data showed that Iran can be considered a new region of high potential for distribution of cannabis landraces with diverse THC and CBD content, predominantly falling into three groups, as Type I = THC-predominant, Type II = approximately equal proportions of THC and CBD (both CBD and THC in a ratio close to the unity), and Type III = CBD-predominant. Correlation analysis among two target cannabinoids and environmental and geographical variables indicated that both THC and CBD contents were strongly influenced by several environmental-geographical factors, such that THC and CBD contents were positively correlated with mean, min and max annual temperature and negatively correlated with latitude, elevation, and humidity. Additionally, a negative correlation was observed between THC and CBD concentrations, suggesting that further studies to unravel these genotype $\times$ environment interactions $(\mathrm{G} \times \mathrm{E}$ interactions) are warranted. The results of this study provide important pre-breeding information on a collection of cannabis that will underpin future breeding programs.
\end{abstract}

Keywords: medical cannabis; hemp; marijuana; gene pool; landrace; phytocannabinoid

\section{Introduction}

Cannabis sativa L. (Cannabinaceae) is an annual herbaceous multi-purpose plant with a long history of human selective breeding [1-5].

The genus Cannabis contains different types of chemicals with a diverse phytocannabinoid profile and range of effects [1]. The differences in phytocannabinoids composition and quantities of cannabis chemotypes should be searched in the genetic background of their biosynthesis pathways and the environmental conditions where they have been evolved [6-8]. Precursor synthesis of cannabinoids occurs from two distinct biosynthesis pathways: the polyketide and the methylerythritol phosphate (MEP) pathways, which produce olivetolic acid (OLA) and geranyl diphosphate (GPP), respectively [5]. Geranylpyrophosphate:olivetolate geranyltransferase catalyse the alkylation of OLA with GPP, leading to formation of CBGA (cannabigerolic acid), the main precursor of various cannabinoids, 
responsible for producing acidic precursors of THC (tetrahydrocannabinolic acid; THCA) and CBD (cannabidiolic acid; CBDA). Naturally these phytocannabinoids exist as both monocarboxylic acids (e.g., THCA, CBDA) and as decarboxylated forms (e.g., THC, CBD); however, heating (at temperatures above $120^{\circ} \mathrm{C}$ ) promotes decarboxylation [9-14].

Different types and concentrations of the cannabinoids, in particular, THC with psychotropic effects and CBD, a non-intoxicating metabolite, alongside applied morphological attributes may underpin the recreational, medicinal, and industrial uses of cannabis [15-23]. The range of $0.3-1 \%$ THC that determines the border of drug-type and non-drug type cannabis of course seems to be only a widely accepted agreement to determine the restrictions of cultivation in different countries [24-28]. Nowadays, there is intense competition for finding unique chemotypes or varieties with low THC $(<0.2-0.3 \%$ dry weight $)$ and high CBD contents that can be industrially used or cultivated [10,29-34].

Despite high potential as a multipurpose plant to produce drugs, fiber-based products, nutritional supplements and seed oil, and cosmetics, there remain critical gaps in knowledge. The recent discoveries of a variety of medical cannabis with different preparations to treat and or cure a number of serious disorders and its newly discovered industrial applications have given momentum to the quest for exploring, exploiting, and protecting natural resources with commercial potential [35-38].

The quantity and composition of cannabinoids, in particular, THC and CBD, have been targeted by extensive research by breeders, the scientific community, and legislative authorities for almost half a century $[5,8,39]$.

Here, we considered that concentration and the ratio of THC/CBD could be the crucial key points for the initiation of a breeding program towards different end products in the huge cannabis/hemp market. Although cannabis has a long history of cultural use in Iran, there is little detailed information about the Iranian cannabis market, including the chemical characteristics of the locally available cannabis landraces, which are stored in the CGRC gene bank. To complete the puzzle, the current study was conducted as the primary report of screening THC and CBD contents of 20 selected native cannabis populations collected from different locations in Iran towards initiating anew breeding program for different industrial and medical purposes.

\section{Results}

\subsection{THC and CBD Quantification and Phenotyping}

The study of chemical patterns and profiling of novel cannabis germplasm grown in highly diverse climates and geographical regions are likely to valuable and informative as a starting point for future cannabis breeding programs. HPLC-derived chromatograms of the extracts from the female buds and standards solution are shown in Supplementary Figure S1.

Variation of THC and CBD composition of cannabis plants derived from 20 locations indicate that this collection is diverse in THC and CBD both within and between populations, and that phenotypes characterized by THC/CBD values could be classified into three classes: Type I (THC-predominant), Type II (approximately equal proportions of THC and CBD), and Type III (CBD-predominant). Furthermore, studied populations were completely different in terms of many morphophysiological features, which is beyond the scope of this study, but the plants of three unique dwarf and early flowering populations with compact inflorescence including Pir-01, Sqz-01, and Naq-01 were all located chemically in the group of Type I. Additionally, the plants of location Ard-01, which was morphologically distinct in terms of inflorescence structure, seeding time, and seed size, surprisingly, it failed to classify into either THC-predominant or CBD-predominant groups. The majority of plants of this population with almost equal concentration of THC and CBD, hereafter, a ratio of $\mathrm{THC} / \mathrm{CBD} \approx 1$, were defined as Type II. The different structure of female inflorescences and buds in studied populations is presented in Figure 1. 
Pir-01

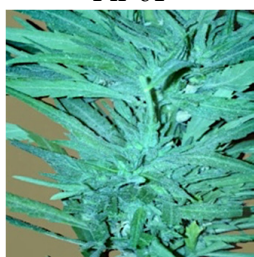

Sqz-01

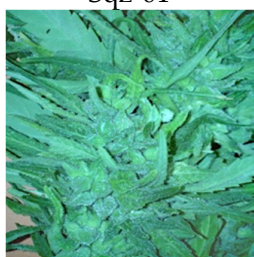

Rmhz-01

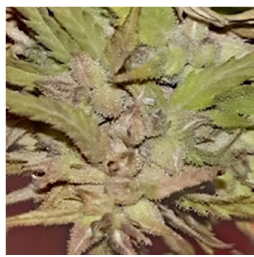

Abh-01

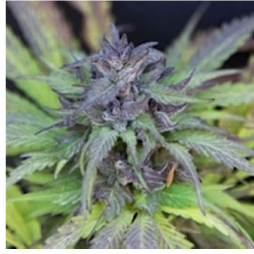

Bam-01

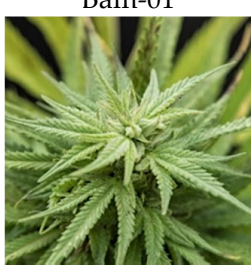

San-01

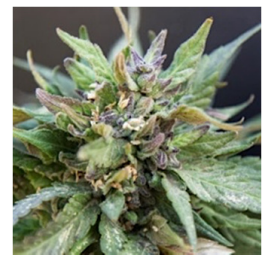

Sir-01

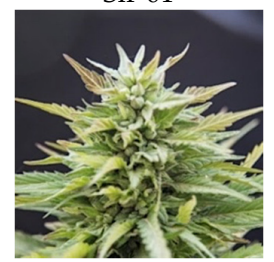

Ark-01

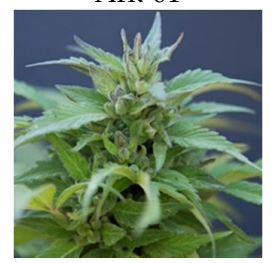

Sam-01

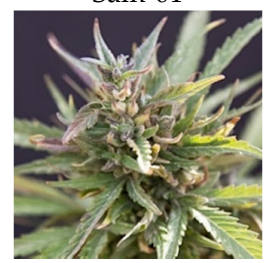

Bsh-01

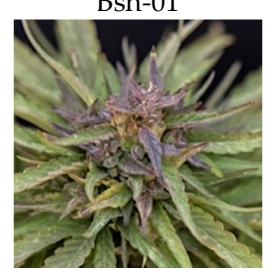

Nhv-01

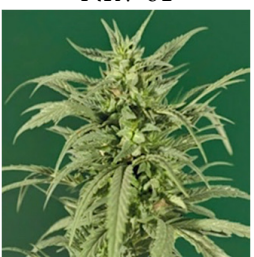

Ard-01

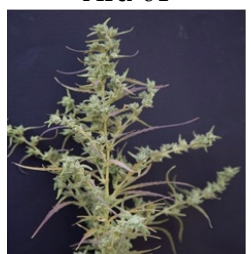

Qzv-01

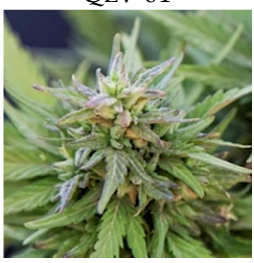

Krmn-01

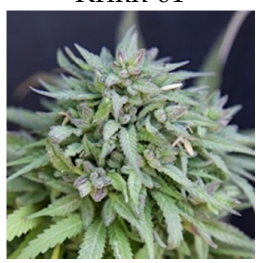

Dez-01

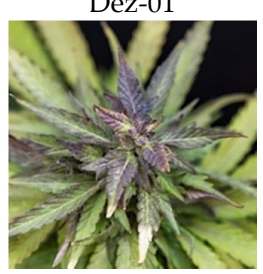

Ban-01

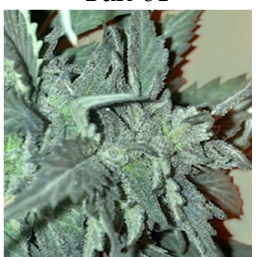

Zah-01

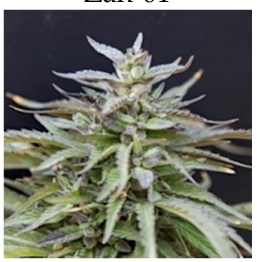

Naq-01

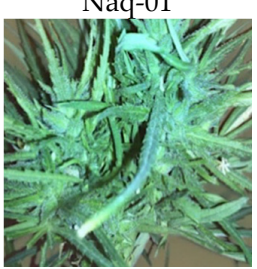

Krsh-01

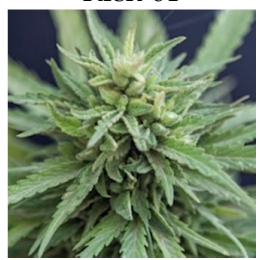

Dez-02

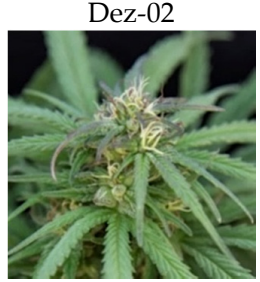

Figure 1. Diversity in female inflorescence of 20 natural cannabis populations distributed across Iran from west and north-west to south-west and east and south-east.

Our results illustrated that maximum THC was observed in the plants collected from locations Dez-02 and Dez-01 distributed in the south-west areas. The minimum THC was quantified from plants from the location Sam-01, the maximum CBD was obtained from the plants of location Rmhz-01, and the minimum CBD was obtained from Pir-01 (Figures 2 and 3a). A significant variation in THC content from $0.02 \%$ to $15.66 \%$ and CBD from $0.03 \%$ to $15.89 \%$ (\% DW) were observed in this collection (Figure 2). The distribution of THC and CBD concentration (\%) for each location is shown in Figure 2. A greater THC/CBD amount can be recorded due to high THC or low CBD levels. The populations of this collection with a prevalence of THC and THC/CBD content well beyond 1.0, including Pir-01, San-01, Sqz-01, Zah-01, Qzv-01, Naq-01, Abh-01, Krmn-01, Krsh-01, Bsh-01, Bam01, Dez-01, and Dez-02, are defined as Type I. Additionally, six populations, including Nhv-01, Ban-01, Sir-01, Rmhz-01, Ark-01, and Sam-01, with a prevalence of CBD, hereafter, THC/CBD well below 1.0, were considered CBD- predominant populations [8,29-33,40]. Among CBD-predominant populations, all plants of population Sam-01 were characterized with THC level $\leq 0.3 \%$. The phenotype of each population based on THC/CBD ratio is 
given in Figure 3a. As we observed THC and CBD diversity both between and within studied populations, so did we measure the abundance (\%) of each phenotype (Type I, Type II, and Type III) per population in terms of the ratio of THC/CBD (Figure 3b). In order to define the phenotype of a population, we have considered the phenotype that is dominant in that population (Figure 3a); then, we have shown the abundance of all existed phenotypes in that population as well (Figure 3b). All plants of population Ard-01 had approximately equal proportions of THC and CBD, and three populations of Ban-01, Ark-01 and Sam-01 were 100\% CBD- predominant and all their individuals assigned to the group of Type III (Figure 3b).

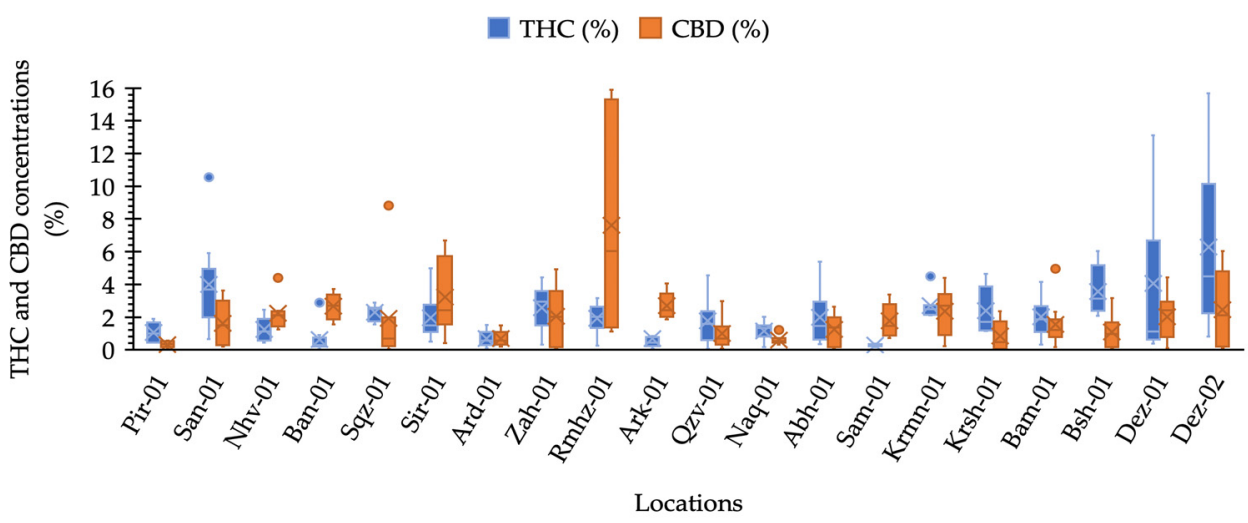

Figure 2. Box plot analysis of CBD and $\triangle-9-\mathrm{THC}$ concentration (\%) distribution measured for pistillate cannabis plants in each location.

(a)

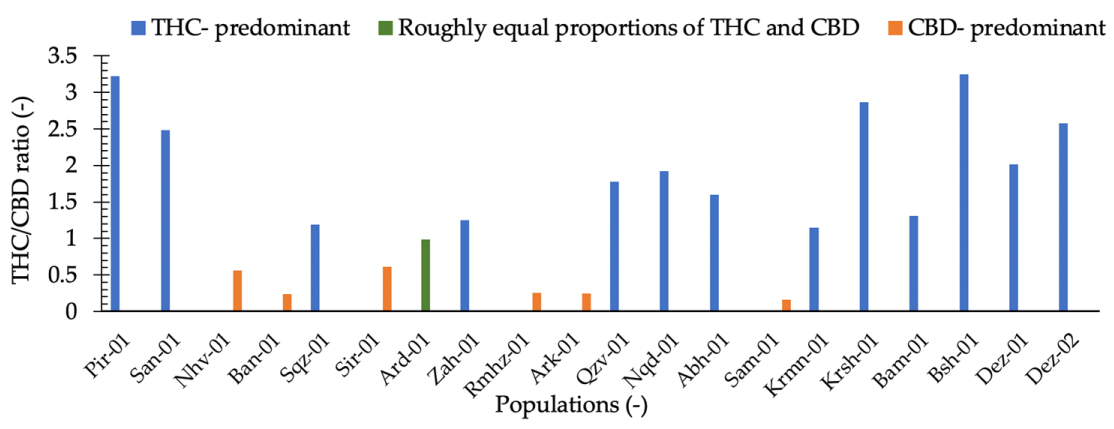

(b)

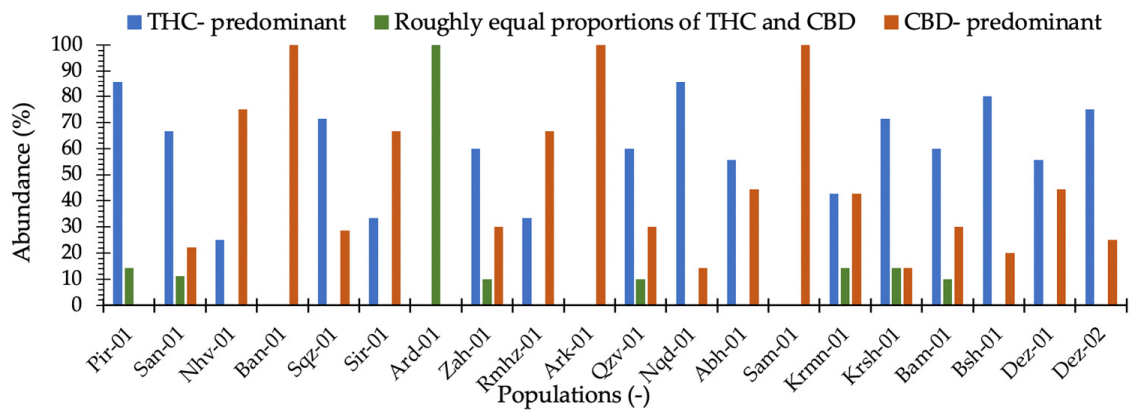

Figure 3. (a) THC/CBD ratio has been classified populations in three chemical phenotype groups including THC/CBD $>1$ (Type I or THC-predominant), THC/CBD $\approx 1$ (Type II or approximately equal proportions of THC and CBD), and THC/CBD < 1 (Type III or CBD-predominant); (b) the abundance (\%) of Type I, Type II, and Type III plants measured for each location. 


\subsection{Correlation between the Climatic and Geographical Parameters and THC and CBD} Quantity Variation

We considered all 13 parameters including statistics of latitude, longitude, elevation, $\mathrm{P}$, Tmean, Tmin, Tmax, RHmean, RHmin, RHmax, SD, WS, DP (abbreviations are explained in detail in the Materials and Methods section "climatic and geographical data"), and THC and CBD concentration (\%) obtained for the plants of each location to estimate the Pearson correlation coefficient among these variables. Our results showed that there was a negative correlation between THC and CBD concentration, but this was not significant $(\mathrm{r}=-0.053)$. Latitude had a negative significant correlation with both THC and CBD $(\mathrm{r}=-0.157, p \leq 0.05 ; \mathrm{r}=-0.239, p \leq 0.01$, respectively). In addition, elevation correlated negatively with THC and CBD, and this was significant $(\mathrm{r}=-0.408, p \leq 0.01 ; \mathrm{r}=-0.222$, $p \leq 0.01$, respectively)

Moreover, we observed a significant negative correlation for wind and THC concentration $(\mathrm{r}=-0.326, p \leq 0.01)$. All three statistics related to temperature, including Tmean, Tmin, and Tmax, showed a positive correlation with THC ( $\mathrm{r}=0.352, p \leq 0.01, \mathrm{r}=0.292$, $p \leq 0.01, \mathrm{r}=0.412, p \leq 0.01$, respectively; Table 1$)$, as well as CBD content $(\mathrm{r}=0.314, p \leq 0.01$, $\mathrm{r}=0.311, p \leq 0.01, \mathrm{r}=0.287, p \leq 0.01$, respectively; Table 1). Additionally, all three relative humidity statistics comprising RHmean, RHmin, and RHmax correlated negatively with CBD content $(\mathrm{r}=-0.201, p \leq 0.05, \mathrm{r}=-0.171, p \leq 0.05, \mathrm{r}=-0.188, p \leq 0.05$, respectively), and RHmin correlated negatively with THC content $(\mathrm{r}=-0.206, p \leq 0.01)$. In addition, to assess the correlation of each parameter, we performed PCA on THC and CBD content of all studied individuals and climatic and geographical variables of sampled regions (Figure 4). The PCA plot revealed a negative correlation for elevation and confirmed the positive correlations of the three temperature statistics including Tmean, Tmin, and Tmax with THC and CBD content (Figure 4).

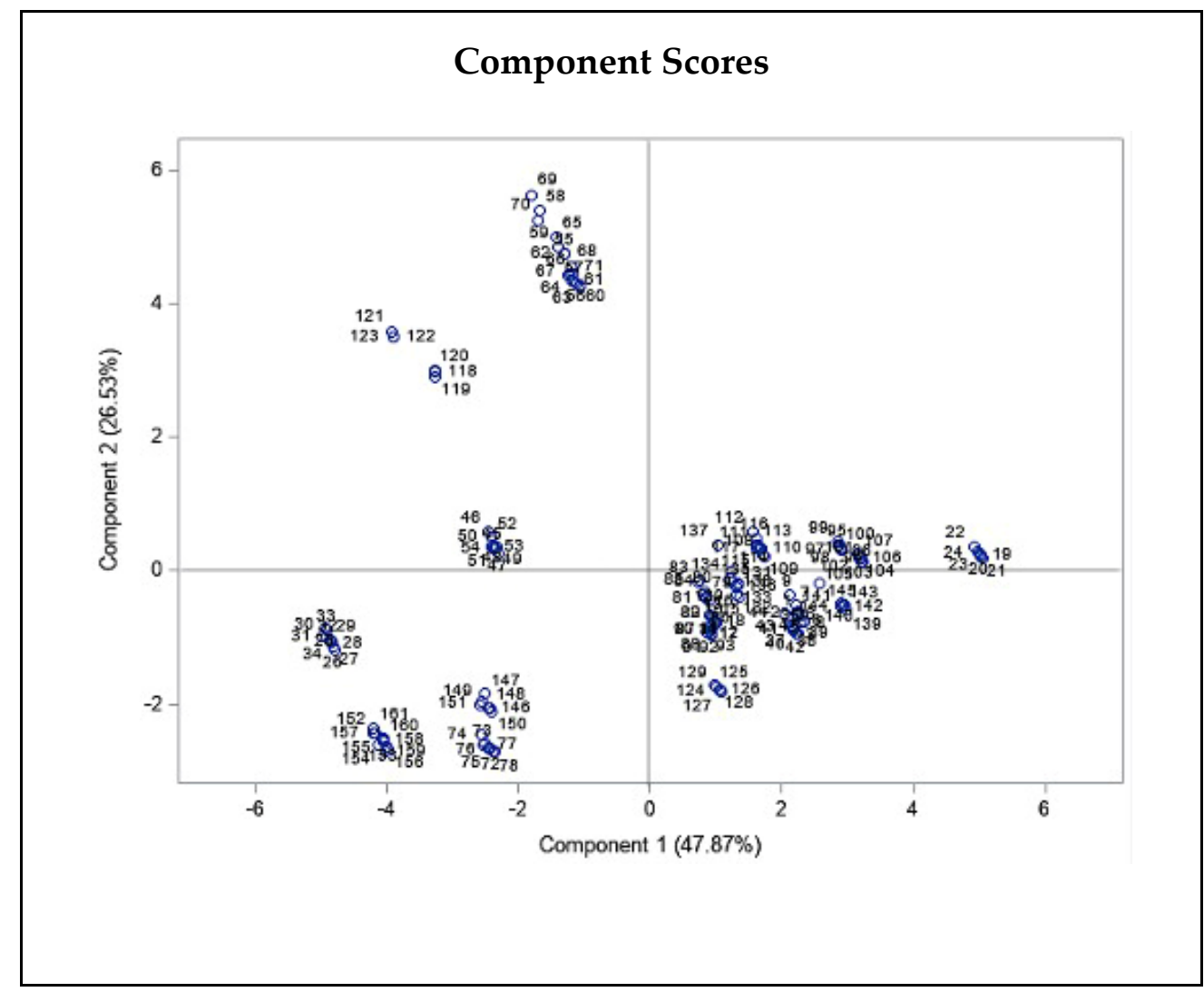

Figure 4. Cont. 


\section{Component Variables}

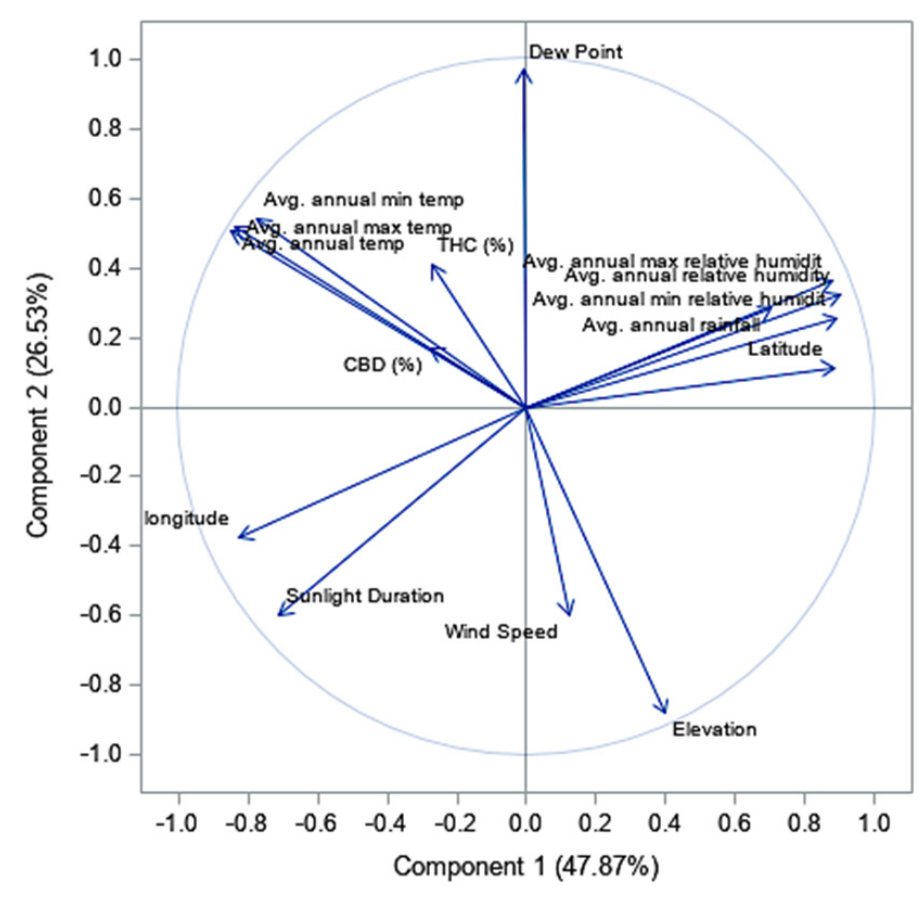

Figure 4. Principal component biplot consist of PCA scores of individuals (dots-first graphic) and loadings of variables (vectors-second graphic) of THC and CBD contents of 20 Iranian cannabis populations and geographical/climatic variables of regions of origin. PC1 and PC2 explain most of the variance in the original variables. Average annual temperature and latitude strongly influences PC1, while elevation and sunlight duration have more say in PC2. The loading plot shows THC and CBD contents positively correlate with mean, min, and max annual temperature and negatively correlate with elevation, latitude, and humidity statistics. 
Table 1. Pearson correlation among geographical and climatic parameters with THC and CBD concentration in the studied cannabis plants.

\begin{tabular}{|c|c|c|c|c|c|c|c|c|c|c|c|c|c|c|c|}
\hline \multicolumn{16}{|c|}{ Variables } \\
\hline & THC & CBD & $\begin{array}{l}\text { Longitude } \\
\text { (E) }\end{array}$ & $\begin{array}{l}\text { Latitude } \\
\text { (N) }\end{array}$ & $\begin{array}{l}\text { Elevation } \\
\text { (m) }\end{array}$ & WS $^{1}$ & Tmean $^{2}$ & $\operatorname{Tmin}^{3}$ & $\operatorname{Tmax}{ }^{4}$ & RHmean ${ }^{5}$ & RHmin $^{6}$ & $\operatorname{RHmax}^{7}$ & $\mathrm{SD}^{8}$ & $P^{9}$ & DP 10 \\
\hline THC & 1 & $\begin{array}{c}-0.053 \\
\text { NS }\end{array}$ & $0.118^{\mathrm{NS}}$ & $-0.157 *$ & $-0.408^{* *}$ & $-0.326^{* *}$ & $0.352 * *$ & $0.292 * *$ & $0.412^{* *}$ & $-0.103^{N S}$ & $-0.206^{* *}$ & $\begin{array}{c}-0.057 \\
\text { NS }\end{array}$ & $\begin{array}{c}-0.039 \\
\text { NS }\end{array}$ & $\begin{array}{c}-0.114 \\
\text { NS }\end{array}$ & $0.305^{* *}$ \\
\hline CBD & $\begin{array}{c}-0.053 \\
\text { NS }\end{array}$ & 1 & $0.042^{\mathrm{NS}}$ & $-0.239 * *$ & $-0.222^{* *}$ & $\begin{array}{c}-0.040 \\
\text { NS }\end{array}$ & $0.314^{* *}$ & $0.311^{* *}$ & $0.287^{* *}$ & -0.201 * & $-0.171^{*}$ & $-0.188^{*}$ & $0.150^{\mathrm{NS}}$ & $\begin{array}{c}-0.028 \\
\text { NS }\end{array}$ & $0.149^{\mathrm{NS}}$ \\
\hline
\end{tabular}

${ }^{* *}$ Correlation is significant at the 0.01 level; ${ }^{*}$ Correlation is significant at the 0.05 level; ${ }^{\mathrm{NS}}$, non-significant. ${ }^{1}$ Wind speed. ${ }^{2}$ Average annual temperature. ${ }^{3}$ Average annual minimum temperature. ${ }^{4}$ Average annual maximum temperature. ${ }^{5}$ Average annual relative humidity. ${ }^{6}$ Average annual minimum humidity. ${ }^{7}$ Average annual maximum humidity. ${ }^{8}$ Sunshine duration. ${ }^{9}$ Average annual precipitation. ${ }^{10}$ Dew point. 


\section{Discussion}

\subsection{THC and CBD Diversity}

In this study, we have found that Iran is a rich natural resource of cannabis with a high level of THC and CBD diversity, both among and within populations, and this can be attributed to genetic diversity, age, nutrition, geographical, and bioclimatic factors influencing plant chemistry [41-43].

The greatest THC variation within locations was obtained for plants from locations of Dez-02 and Dez-01 and the greatest CBD variation was found for plants in Rmhz-01 (Figure 2). In addition, the phenotype diversity was found within locations, so that all three types of I, II, and III with various abundances were found within six locations of San-01, Zah-01, Qzv-01, Krmn-01, Krsh-01, and Bam-01 (Figure 3b). The diversity within these populations can help genetic erosion reduction [44].

All individuals of three populations of Ban-01, Ark-01, and Sam-01 belonged to the type III (CBD- predominant), and all plants of Ard-01 assigned to Type II (roughly equal proportions of THC and CBD), indicating that these populations are more chemically homogeneous compared to other populations.

\subsection{Morphological Features and Phenotyping}

The populations under study differed in morphological features including total height (tall, mid, or dwarf), thin or squat growth, leaf shape, phyllotaxy, number of nodes, number of lateral inflorescences, internode length, compact or non-compact inflorescence, flowering time (fast, mid, or late), seeding time (fast, mid, or late), seed features, etc., and although not reported here, this is in line with earlier research reported that chemical phenotypes can be characterized by different morphological features [8]. Danziger and colleagues (2021) reported architecture of cannabis plant may considerably affect the cannabinoids profile, which has significant pharmaceutical and economic importance [45]. Additionally, phenotype markers that can facilitate preliminary identification and selection as a supplement to chemical and genetic analysis developed in 2021 [46]. They showed significant morphological differences in terms of leaf color, leaflet shape, large and compact inflorescences, and dense and resinous trichomes, which were identified between 21 cultivars covering three chemical phenotypes (THC dominant, CBD dominant and intermediate cultivars). They also reported that modern cannabis cultivars are morphologically distinguished by a morphological feature (leaflet shapes) by users and breeders [46].

Among the studied populations, three dwarf populations including Saq-01, Pir-01, and Naq-01 distributed in the north-west along with 10 other populations were located in the group of Type I (Figure 3a). These three unique populations were assumed to be marijuana, as they have similar features to those reported recently with thinner stems, more branches, and a higher density of floral tissues than industrial hemp plants [8]. In addition, the plants of population of Ard-01 were morphologically (tall, branched with space between branches, branches out and few leaves, early seeds mature, and drop) and chemically (located in the group of Type II) distinct.

\subsection{Phenotyping in Terms of THC and CBD Composition}

Cannabis is an economically important species and is predicted to become a significant commercial crop with unprecedented market growth potential [47]. Recent publication showed among individual cannabis plant parts including roots, leaves, stem bark and inflorescence, cannabis inflorescence was characterized by the highest concentration of cannabinoids in three chemovars [48]. They stated that the comprehensive profile of bioactive metabolites can rediscover therapeutic potential for each part of cannabis from their traditional use [48]. Chemical screening of natural populations can help identify chemical diversity, which is a primary step for improving breeding programs in this plant.

Taken together, the cannabis definitions are different based on scientific and political assignations. The significant difference in cannabinoid content of cannabis is supported by numerous studies showing that the most important classification of cannabis types 
that vary widely among political jurisdictions is that of the drug type and the fiber type (hemp). THC is the major cannabinoid in marijuana types, while CBD predominates in fiber-type hemps $[3,10,32,33,49-52]$. The cultivation of cannabis varieties containing up to $0.2 \% \Delta$-9-THC with no indication of permitted percentage of the other compounds, first of all being non-addictive psychoactive cannabidiol (CBD), have been recently allowed by two European regulations and Italian law. These varieties have been used for food, oils, fiber, powder, and bioengineering [41]. Recent studies on chemical composition and quantification of hemp industrial varieties indicated $\triangle 9$-THC content was lower compared to other cannabinoids. Additionally, $\triangle 8$-THC was detected only in one hemp oil sample at too low a concentration [53]. Additionally, a report in 2019 indicated that, among several cannabinoids, only CBDA was determined to show a different concentration in hemp inflorescences samples. Additionally, according to their study, THCV was not found in the hemp inflorescence samples analyzed, and $\Delta-9$-THC and $\Delta-8$-THC were detected at low concentrations, below the legal limit. Therefore, their results confirmed the classification of the studied samples as fiber [54]. In order to grow consumer interest in hemp oilseed supplements, four main cannabinoids of CBD, CBDA, CBN, and $\triangle-9-T H C$ in an oil matrix of seven commercial hemp oil supplements have been determined [55]. They reported that the cannabinoid composition is required to be monitored in such supplements, as in some cases, the cannabinoids concentration in analyzed samples differed significantly from those declared by the manufacturers [55].

In addition, cannabis chemotypes have been reported using the biochemical composition, in particular, the THC/CBD ratio in many publications. Chemical phenotypes (chemotypes) can be used to define cannabis varieties with different chemical variants and different morphological features to classify $C$. sativa into three principal classes differ in their THC/CBD ratios: chemotype I (drug type plants which exhibit a THC/CBD ratio well beyond 1.0 especially due to high THC content); chemotype II (an intermediate ratio of 0.5-2.0); and chemotype III (fiber-type plants that have a ratio well below 1.0, with a prevalence of CBD) [8]. Additionally, cannabis varieties were classified into three groups: chemotype I (total THC/total CBD ratio $\geq 1.0$ ), intermediate type (chemotype II), which has an intermediate ratio close to 1.0, and chemotype III, which exhibit a low total THC/total $\mathrm{CBD}$ ratio $\leq 1.0$ [3]. On the other hand, three main classes of cannabis have been suggested based on THC/CBD ratio: THC-type plants with THC/CBD $\geq 10$, intermediate-type plants with $\mathrm{THC} / \mathrm{CBD} \approx 1$, and CBD-type plants with $\mathrm{THC} / \mathrm{CBD} \leq 0.1[56,57]$. Marchei and colleagues (2020) stated that, while the THC content in light cannabis has to be within $0.2 \%$, CBD content is highly variable, ranging from 2 to $40 \%$ [41]. Additionally, serum THC/CBD concentration ratio was used as a useful biomarker to identify use of light cannabis (not higher than 0.9), illegal THC cannabis (generally $>10$ ), and medical cannabis $(>1)$ [35].

Another study on chemotaxonomic discrimination indicated significant chemical differences in three chemotypes, so that CBD dominant varieties had higher amounts of total CBD, while THC dominant varieties had higher total THC, and intermediate varieties were generally equal to or in between those in CBD-dominant and THC-dominant varieties [58]. They finally showed that chemotype markers (presence or absence of THC and $\mathrm{CBD}$ ) could be used as chemical fingerprints for quality standardization or variety identification for clinical studies and cannabis product manufacturing [58]. THC and CBD variations among populations of this Iranian collection enabled us to define studied populations as three different groups: Type I (THC/CBD > 1), Type II (THC/CBD $\approx 1)$, and Type III (THC/CBD < 1) with a prevalence of THC, both THC and CBD in an approximately equal proportions, and CBD, respectively (Figure 3a).

Genetic diversity in Iranian cannabis germplasm has been assessed by merging the data with the marijuana and hemp data prepared by [59] to elucidate the relationship of Iranian cannabis with marijuana and fiber type accessions. Finally, they categorized Iranian cannabis populations into marijuana and hemp clusters and reported that natural populations of cannabis in Iran in general more closely fit the profile of marijuana than hemp [60]. Additionally, in this study, we have used the same sources to fingerprint THC 
and CBD, and these populations were defined as Type I, Type II, and Type III, thus revealing, on the basis of chemistry, these three distinct types.

In this research, most plants of population Ard-01, which were also morphologically distinct with a THC/CBD ratio around one due to equivalent THC and CBD concentrations, were assigned to class Type II, defined as an intermediate THC/CBD ratio. This supports the findings of a genetic diversity study reported earlier, indicating Ard-01 was failed to group with either the marijuana or hemp clusters [60]. This is an interesting finding and may have immediate significance for commercialization, promising for therapeutic purposes in the production of medications with formula requirement of THC/CBD ratio around the unity such as Sativex ${ }^{\circledR}$ [61]. This is an important medication for the suppression of spasticity and pain associated with multiple sclerosis [13,62]. It is worth noting that sequencing the whole genome of this morphologically, chemically, and genetically distinct population would be of value, as this should provide further insight into the genetic basis of the three chemotypes described here.

Furthermore, a concentration of THC $\leq 0.3 \%$ and higher amount of CBD in the plants from the location Sam-01 that was located in class Type III is another significant finding in this study, worthy of further investigation, and may reflect a tight control of cannabinoid type and content for cultivation and could provide pre-breeding germplasm resources for future development of hemp crops, particularly in nations where there is a strict regulatory environment around the production of high THC crops.

Although most of the focus has been on identifying plants with higher concentrations of THC for the recreational drug industry, and those with higher concentrations of CBD for medicinal, fiber, and grain purposes, there is also evidence reporting therapeutic benefits for CBD with anticonvulsive, anti-epileptic, antimicrobial, and antiparkinsonian properties, which are more important recently due to the lack of psychotropic effects associated with CBD consumption, as well as FDA-approved CBD drugs such as Epidiolex ${ }^{\circledR}$ [63-68]. Berman and colleagues (2018) found that, despite the similarity in CBD contents, not all equally high-CBD cannabis extracts produced the same effects. They stated that, as cannabinoids profiling of diverse medical cannabis plants are different, analyzing the effects of specific cannabis compositions for pharmacological-based research is critical [69]. Therefore, it seems likely in the future that both THC and CBD content may be of wide relevance for further development within the pharmaceutical industry [68]. This is supported by a previous study reported that the combination of the psychoactive cannabis $\triangle 9$-THC with other non-psychotropic cannabinoids such as CBD demonstrated a higher activity than THC alone [70,71]. Additionally, previous findings showed that all three major products-food, fiber, and medicine-were extracted from the same crop of the accessions from Darchula district in the northwest of Nepal [72]. In addition, some Iranian cannabis populations were evaluated using wood and fiber anatomy and stem biometry characteristics [73]. They suggested that both populations of Bsh-01 and Zah-01 are significant candidates in terms of fiber anatomy, fiber length, and stem biometry and can be considered for textile and paper industries, while in this study, the aforesaid populations were defined as Type I and, despite the prevalence of THC, also have eligible fiber anatomy characteristics.

Our research showed that populations of Nhv-01, Ban-01, Sir-01, Rmhz-01, Ark-01, and Sam-01 are defined as Type III. However, in the earlier study, some populations are expected to be putative high-potential fiber populations, indicating that both populations Ban-01 and Nhv-01 have strong fiber characteristics such as a higher average of bast and woody cores and, alongside populations of Rmhz-01 and Ark-01, can be considered an option for breeding programs towards producing fiber [73].

The results of this study contribute important pre-breeding information for cannabis breeders to improve breeding programs utilizing this collection. Although the uses of these populations cannot be predicted with certainty, as accessions high in THC or high in CBD are Type I and III, respectively, they are not necessarily "hemp" or "medicinal marijuana" in the classic sense; however, according to previous study using genomic data, Iranian populations were located in two distinct marijuana and hemp clusters [60]. Therefore, 
populations of this collection assumed to offer a range of measurable health benefits in the pharmaceutical, dietary supplement industries, dual-proposal (seeds and fiber), and even renewable and sustainable feedstock for the production of biofuels [5,74-77]. Further studies are needed to evaluate the potential of these populations. Additionally, fiber anatomy is required to assess for fiber production purposes.

\subsection{Effect of Climatic and Geographical Characteristics on THC and CBD Content Variation}

In general, correlation analysis and PCA results revealed a positive correlation between temperature variables and the two target chemical metabolite contents, and a negative correlation between latitude as well as elevation and metabolites content (Table 1; Figure 4). It is clear that higher temperatures promote cannabinoid biosynthesis, as found in this research. We also found a negative correlation between THC and CBD concentrations, but it was not significant. The THC and CBD biosynthesis pathways have been elucidated and show that cannabigerolic acid (CBGA) is a prerequisite for both CBD and THC biosynthesis and then follows two pathways to synthesize carboxylic acids (THCA or CBDA), and these acidic forms of cannabinoids, upon heating or smoking, decarboxylate to their neutral forms (THC and CBD) $[13,21]$. THCA synthase and CBDA synthase enzymes that catalyze the reaction of THCA to THC and CBDA to CBD, respectively, compete with each other for CBGA and expedite neutral cannabinoids creation and their levels. The negatively correlation between latitude and THC and CBD contents supported by a study reported that latitude decreases can result in cannabinoids level reduction, and plants from high latitudes exhibited a low $\triangle 9$-THC [78].

Moreover, this study indicated that the populations at the high elevation showed a trend towards lower concentrations of THC and CBD. For example, Sam-01 at $1858 \mathrm{~m}$ above sea level (maximum value of elevation) had lower cannabinoids, and Dez01, Dez-02, and Bsh-01 at a low elevation had higher amounts of THC and CBD compared to other locations studied. The two populations located in the warmest state of Iran, including Dez01 and Dez-02, had the highest concentrations of THC, consistent with the positive effect of temperature on cannabinoid accumulation and growth. Overall, these results showed that environment is also likely to play a role in cannabinoids concentration, suggesting that controlled environment studies or multi-year trials should be completed to further elucidate the importance of these $\mathrm{G} \times \mathrm{E}$ interactions.

\section{Materials and Methods}

\subsection{Genetic Resources}

Twenty natural dioecious cannabis populations selected from the native cannabis gene pools across Iran (CGRC; www.medcannabase.org). These populations were located in distinct geographical and climatic regions (included cold and mountainous regions of the west and north-west, warm and wet regions of the south-west, and warm and dry regions of the east and south-east areas) (Table 2; Figure 5, Supplementary Table S1). At least 10 female plants per population were used for phytochemical analysis if available (Table 2). In addition, seeds were collected from labeled local populations to grow for future studies. Geographical information was recorded and used to determine climatic parameters of sampled regions.

In order to minimize sampling bias, analyses were performed on female flower buds as the major sources of glandular trichomes, the main tissue for phytocannabinoids accumulation $[8,9,11,32,50,57,79,80]$. Due to a diverse phenological pattern among 20 populations, terminal inflorescences were collected before seed appearance, when trichomes turned $50-70 \%$ amber and the rest remained clear to capture the highest concentration of THC and CBD for quantitative analysis (Table 2). 
Table 2. Geographical data of native cannabis genotypes were collected from different selected regions of Iran.

\begin{tabular}{|c|c|c|c|c|c|c|c|c|c|}
\hline Country & Province & $\begin{array}{l}\text { Location } \\
\text { Code }\end{array}$ & $\underset{\text { Size }}{\text { Sample }}$ & $\begin{array}{l}\text { Elevation } \\
\text { (m) }\end{array}$ & $\begin{array}{c}\text { Longitude } \\
\text { (E) }\end{array}$ & $\begin{array}{l}\text { Latitude } \\
\text { (N) }\end{array}$ & $\begin{array}{c}\text { Annual Average } \\
\text { Temperature } \\
\left({ }^{\circ} \mathrm{C}\right)\end{array}$ & $\begin{array}{c}\text { Annual } \\
\text { Rainfall } \\
(\mathrm{mm})\end{array}$ & $\begin{array}{c}\text { Seed to } \\
\text { Harvest } \\
\text { (Day) }\end{array}$ \\
\hline Iran & $\begin{array}{c}\text { West } \\
\text { Azerbaijan }\end{array}$ & Pir-01 & 7 & 1572 & $45^{\circ} 08^{\prime}$ & $36^{\circ} 42^{\prime}$ & 13.28 & 640.61 & 50 \\
\hline Iran & Kurdistan & San-01 & 9 & 1464 & $46^{\circ} 99^{\prime}$ & $35^{\circ} 31^{\prime}$ & 14.00 & 375.10 & 209 \\
\hline Iran & Hamadan & Nhv-01 & 8 & 1666 & $48^{\circ} 25^{\prime}$ & $34^{\circ} 15^{\prime}$ & 14.72 & 385.29 & 198 \\
\hline Iran & Kurdistan & Ban-01 & 10 & 1503 & $45^{\circ} 53^{\prime}$ & $35^{\circ} 59^{\prime}$ & 14.26 & 660.88 & 206 \\
\hline Iran & Kurdistan & Sqz-01 & 7 & 1480 & $46^{\circ} 26^{\prime}$ & $36^{\circ} 24^{\prime}$ & 11.20 & 439.37 & 53 \\
\hline Iran & Kerman & Sir-01 & 6 & 1754 & $55^{\circ} 68^{\prime}$ & $29^{\circ} 43^{\prime}$ & 17.81 & 138.52 & 207 \\
\hline Iran & $\begin{array}{c}\text { Ardabil } \\
\text { Sistan and }\end{array}$ & Ard-01 & 6 & 1339 & $48^{\circ} 29^{\prime}$ & $38^{\circ} 24^{\prime}$ & 9.12 & 273.67 & 165 \\
\hline Iran & $\begin{array}{l}\text { Balochis- } \\
\text { tan }\end{array}$ & Zah-01 & 10 & 1352 & $60^{\circ} 86^{\prime}$ & $29^{\circ} 49^{\prime}$ & 19.30 & 73.58 & 208 \\
\hline Iran & Khuzestan & Rmhz-01 & 6 & 179 & $49^{\circ} 59^{\prime}$ & $31^{\circ} 27^{\prime}$ & 27.67 & 280.49 & 210 \\
\hline Iran & Markazi & Ark-01 & 9 & 1722 & $49^{\circ} 42^{\prime}$ & $34^{\circ} 04^{\prime}$ & 14.04 & 297.75 & 200 \\
\hline Iran & Qazvin & Qzv-01 & 10 & 1315 & $49^{\circ} 86^{\prime}$ & $36^{\circ} 47^{\prime}$ & 13.91 & 311.85 & 183 \\
\hline Iran & $\begin{array}{c}\text { West } \\
\text { Azerbaijan }\end{array}$ & Naq-01 & 7 & 1324 & $45^{\circ} 22^{\prime}$ & $36^{\circ} 57^{\prime}$ & 14.08 & 323.95 & 58 \\
\hline Iran & Zanjan & Abh-01 & 9 & 1543 & $49^{\circ} 02^{\prime}$ & $36^{\circ} 28^{\prime}$ & 12.39 & 301.31 & 179 \\
\hline Iran & Hamadan & Sam-01 & 6 & 1858 & $48^{\circ} 70^{\prime}$ & $34^{\circ} 20^{\prime}$ & 13.53 & 324.79 & 198 \\
\hline Iran & Kerman & Krmn-01 & 7 & 1761 & $56^{\circ} 58^{\prime}$ & $30^{\circ} 15^{\prime}$ & 17.01 & 123.43 & 185 \\
\hline Iran & Kermanshah & Krsh-01 & 7 & 1389 & $47^{\circ} 03^{\prime}$ & $34^{\circ} 19^{\prime}$ & 15.51 & 402.63 & 206 \\
\hline Iran & Kerman & Bam-01 & 10 & 1068 & $58^{\circ} 14^{\prime}$ & $29^{\circ} 09^{\prime}$ & 23.74 & 54.05 & 208 \\
\hline Iran & $\begin{array}{l}\text { South } \\
\text { Khorasan }\end{array}$ & Bsh-01 & 10 & 881 & $57^{\circ} 43^{\prime}$ & $34^{\circ} 03^{\prime}$ & 21.07 & 79.98 & 174 \\
\hline Iran & Khuzestan & Dez-01 & 9 & 144 & $48^{\circ} 42^{\prime}$ & $32^{\circ} 38^{\prime}$ & 24.56 & 389.40 & 206 \\
\hline Iran & Khuzestan & Dez-02 & 8 & 144 & $48^{\circ} 42^{\prime}$ & $32^{\circ} 38^{\prime}$ & 24.56 & 389.40 & 201 \\
\hline
\end{tabular}

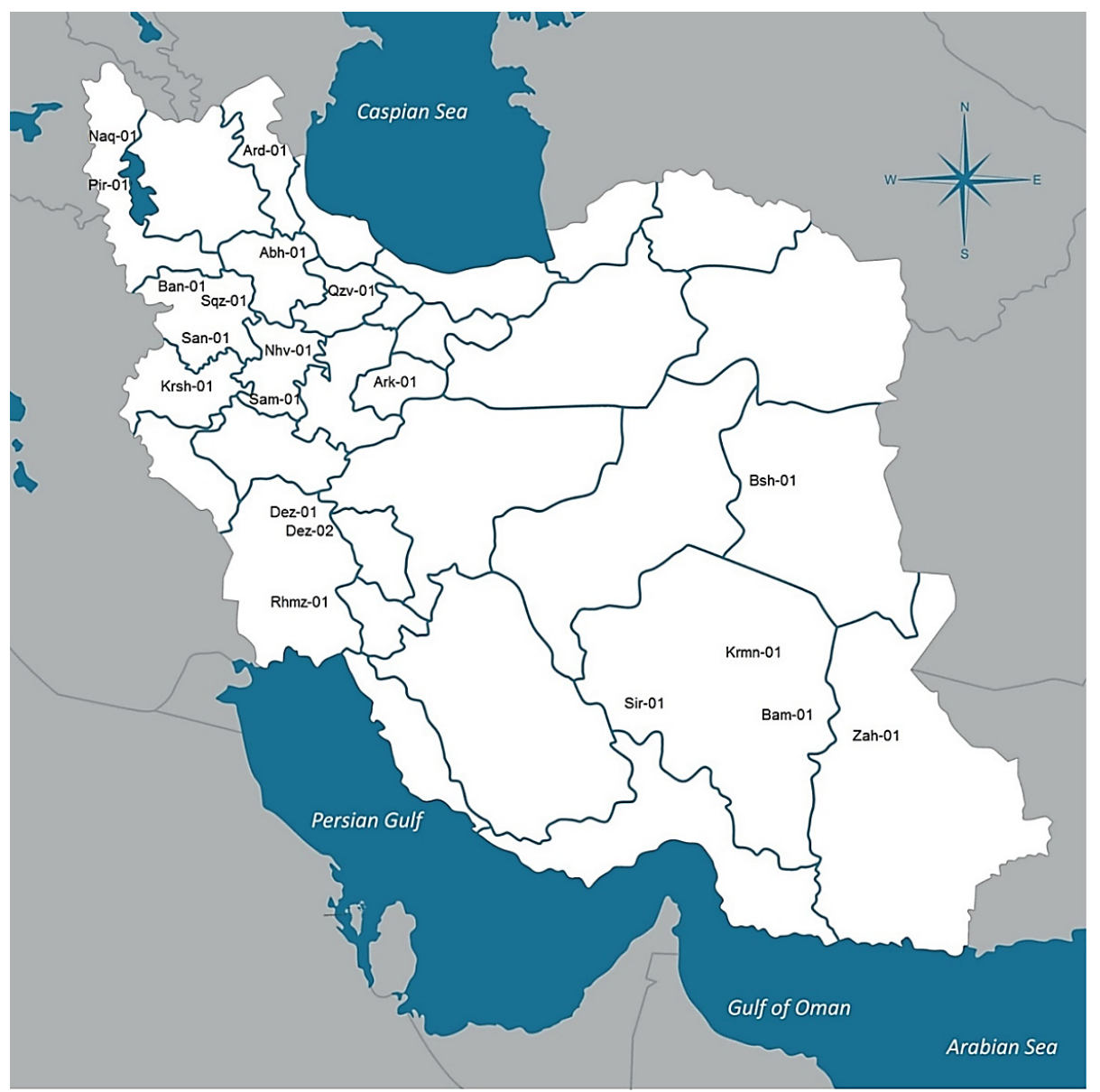

Figure 5. Geographical distribution of 20 distinct cannabis populations across selected regions of Iran. 


\subsection{Sample Preparation}

Fresh plant materials were air dried at room temperature in darkness for up to $14 \mathrm{~d}$ until the leaves become brittle. The drying time varied depending on inflorescence density: plants with compact and tight buds took $14 \mathrm{~d}$, whilst plants with branched buds with space between branches were dried after $7 \mathrm{~d}$. At this stage, the water content of the plant materials was approximately $10 \%$, which was uniform for all populations. Coarse dried female flower buds were then selected, crumbed, and pulverized until ensuring accepted tolerance homogeneity of the samples [81]. A mixture of methanol/chloroform $(v / v: 9 / 1)$ was used as a cannabinoid's extraction solution [3,82-85]. After testing different protocols, sonication was found to be the best process to agitate samples for cannabinoid extraction [86]. Thus, $50 \mathrm{mg}$ of fine tissue powder was weighed and extracted with $2 \mathrm{~mL}$ of a mixture methanol/chloroform $(v / v: 9 / 1)$ by sonication for $40 \mathrm{~min}$ and centrifugation at $10,000 \mathrm{rpm}$ for $15 \mathrm{~min}$ at $10{ }^{\circ} \mathrm{C}$. The upper phase was separated overnight to evaporate the solvent, and residue (dried extract) was dissolved in $1 \mathrm{~mL}$ of HPLC grade MeOH. In order to filter the extract, centrifugation was performed at 13,000 rpm for $10 \mathrm{~min}$. Finally, the supernatant was transferred into an amber vial and $20 \mu \mathrm{L}$ applied for injection to HPLC apparatus.

\subsection{Chemicals}

Cannabinoid reference standards for THC and CBD were purchased from Cerilliant (Sigma Aldrich, USD; TK\#61-65 and TK\#61-477, respectively), and all standards had purity of $100 \%$. All analytical reagent-grade and HPLC-grade solvents used for the extraction procedure were purchased from Merck KGaA (Darmstadt, Germany). Ultrahigh-pure distilled and deionized water was prepared with the Millipore-Q water purification system from Millipore (Kloten, Switzerland).

\subsection{THC and CBD Standard Preparation}

Stock standard solutions containing THC and CBD at a concentration of $1.0 \mathrm{mg} \mathrm{mL}^{-1}$ in methanol were prepared. Working solutions at different concentrations were prepared by dilution of the stock standard solutions with methanol to create calibration curves with linear ranges. Calibrators containing THC and CBD were applied at concentrations of $7.8125,15.625,31.25,62.5,125,250,500$, and $1000 \mu g \mathrm{~mL}^{-1}(w / v)$. Stocks were stored at $-20{ }^{\circ} \mathrm{C}$ in amber sealed glass vials in the dark until analysis.

\subsection{HPLC analysis of Cannabinoids}

The contents of THC and CBD were measured by HPLC. All chromatographic runs were carried out using a Smartline model (Knauer, Berlin, Germany) system equipped with a Smartline pump 1000 (Knauer, Germany), Smartline Manager 5000 degasser $10 \mathrm{~mL}$ (Knauer, Germany), UV-VIS (DAD)- 2800 model, and reversed-phase column C18 column, which was protected by a KNAUER guard column and pre-column (MZ Cartridges $10 \mathrm{~mm}$ ). Data and integration were processed by Software ChromGate (V 3.1.7). The separation was performed using an isocratic flow, and the mobile phase consisted of a mixture of methanol: water in the ratio 80:20 $(v / v)$ as long as the composition stayed the same [22,87]. The injection volume was $20 \mu \mathrm{L}$, and injection was performed via HAMILTON, SYR $50 \mu \mathrm{L}$ (750 N ga 22s/51 mm/pst3). Peaks were monitored at $220 \mathrm{~nm}[24,86,88]$. Flow rate was set

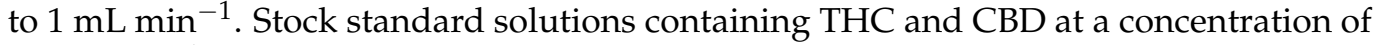
$1.0 \mathrm{mg} \mathrm{mL}^{-1}$ had been prepared in methanol diluted to an appropriate concentration range for construction of calibration curves. THC and CBD peaks were identified and quantified by congruent retention times compared with those of authentic standards obtained. The concentration of THC and CBD in samples were measured using calibration equations $(\mathrm{yCBD}=67191 \mathrm{x}, \mathrm{r} 2=0.9948 ; \mathrm{yTHC}=61827 \mathrm{x}, \mathrm{r} 2=0.9976)$. Column temperature was set at $30{ }^{\circ} \mathrm{C}$. The flowchart of cannabinoids quantification steps is presented in Figure 6. 


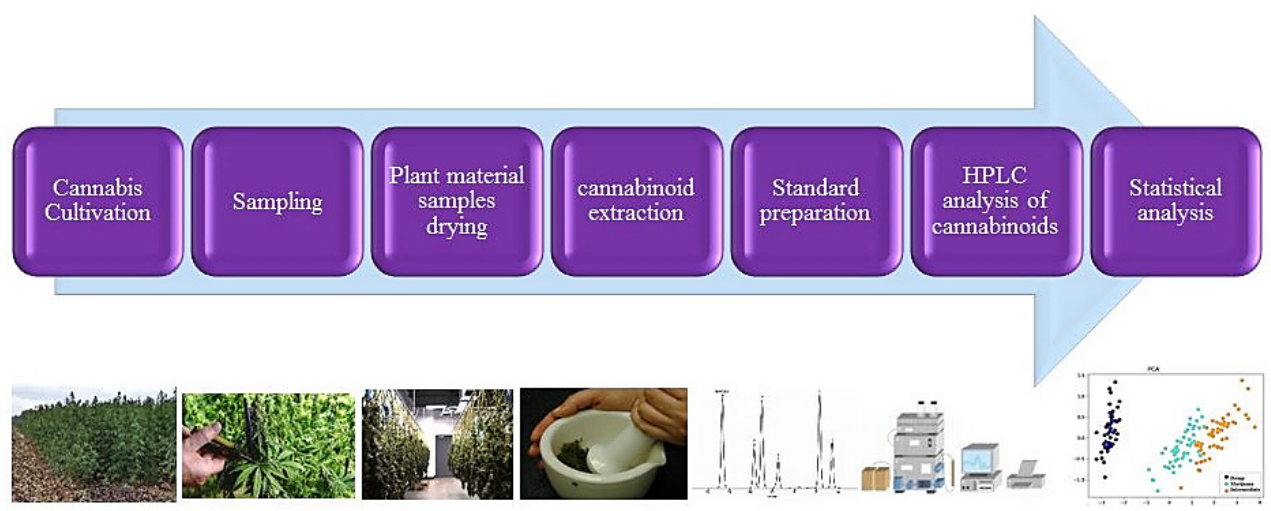

Figure 6. A workflow of cannabinoids assay and quantification.

\subsection{Climatic and Geographical Data}

Climatic data for each site of origin were acquired from the Iran Meteorological Organization (https: / / data.irimo.ir, accessed on 28 November 2019) (Supplementary Table S1). The data set contained a total of 13 variables, including latitude, longitude, elevation, and 10 bioclimatic variables representing average annual precipitation $(\mathrm{P})$, average annual temperature (Tmean), average annual minimum temperature (Tmin), average annual maximum temperature (Tmax), average annual relative humidity (RHmean), average annual minimum relative humidity (RHmin), average annual maximum relative humidity (RHmax), average annual sunshine duration (SD), average annual wind speed (WS), and average annual dew point (DP). Multivariate statistical analysis including PCA was performed on these variables using SAS software, PRINCOMP procedure to reduce high dimensionality of variables and evaluate correlation among them.

\subsection{Statistical Analysis}

Box plot analysis was performed on Excel for THC and CBD diversity in each location using phytochemistry data of THC and CBD contents. The ratio of THC/CBD was used to show different chemotypes of studied populations. Additionally, IBM SPSS statistics software was applied to elucidate the correlation of studied target metabolites concentration and climate factors at site of origin. In other words, a Pearson correlation coefficient was used to determine the relationship between environmental/geographical variables and chemotype to explore the effects of these variables on increase or decrease in two target cannabinoids.

\section{Conclusions}

Starting a successful breeding program in cannabis using a new elite germplasm requires profiling of cannabinoids and terpenes in selected superior chemotypes that harbor ideal morphological characteristics for diverse needs to develop hybrid seeds. A deeper insight into the patterns of recreational, industrial, and medical cannabis use is a high priority for both public health and industry. So far, there is still a great lack of information about chemical composition and cannabinoids profile of Iranian cannabis populations in terms of THC and CBD contents. The present study as a first survey provides a deep insight into THC and CBD profile of 20 natural dioecious cannabis populations morphologically distinct from various geographical regions of Iran and the plausible correlation of these contents with environmental and geographical conditions of regions of origin. The results showed that diverse THC and CBD contents both between and within populations represented three chemical phenotypes as type I (THC-predominant; 13 populations), type II (approximately equal proportions of THC and CBD; 1 population), and type III (CBD- predominant; 6 populations). Ard- 01 with THC/CBD ratio of 1 was chemically distinct, which may increase the capacity of commercialization and medical industries. The THC content of all plants of population Sam-01 characterized with THC 
level $\leq 0.3 \%$ contribute to increase the potential of law enforcement programs in Iran. Additionally, differences in unique and important morphological features of this collection may indicate the difference in their chemical type. Correlations between geography and climate of site of origin were also identified, suggesting that both THC and CBD production were positively and negatively correlated with temperature and latitude, respectively, but more research is required to tease apart these $G \times E$ interactions more fully. In conclusion, our study unravels the natural diversity to delineate cannabis resource with variations in THC and CBD contents and morphological traits, providing a foundation to initiate breeding programs in Iranian cannabis towards different industrial and medical purposes. Therefore, this study will promote future possibilities for the burgeoning cannabis industry in Iran.

Supplementary Materials: The following are available online at https: / www.mdpi.com/article / 10.3390/plants11010129/s1, Table S1: The information of 161 cannabis genotypes analyzed and particular climatic and geographical conditions, Figure S1: (a) HPLC chromatograms of standards solution; (b) methanolic extract of female bud of C. sativa: peak 1: cannabidiol (CBD), peak 2: $\Delta 9$ tetrahydrocannabinol $(\triangle 9-\mathrm{THC})$, data of each of the 20 locations.

Author Contributions: M.M.D. collected the data and performed the experimental lab works, S.A.S. conceived and supervised the work, A.E. supervised the work, G.T. supervised the work and contributed to the data interpretation, A.P. performed the HPLC analysis, S.A.S. and G.T. performed data curation and outputs validation, M.M.D. wrote the original draft, M.M.D., S.A.S., A.E., and G.T. reviewed and edited the manuscript. Funding acquisition was undertaken by BRC (Biopharmaceutical Research Company). All authors have read and agreed to the published version of the manuscript.

Funding: This research received no external funding.

Institutional Review Board Statement: Not applicable.

Informed Consent Statement: Not applicable.

Data Availability Statement: Data are contained within the article or Supplementary Materials.

Acknowledgments: The authors deeply appreciate the Centre for Genetic Resources of Cannabis (CGRC; www.medcannabase.org).

Conflicts of Interest: The authors declare no conflict of interest.

\section{References}

1. Hillig, K.W. Genetic evidence for speciation in Cannabis (Cannabaceae). Genet. Resour. Crop Evol. 2005, 52, 161-180. [CrossRef]

2. Callaway, J.C.; Pate, W.D. Hempseed oil. AOCS 2009, 21, 185-213.

3. De Backer, B.; Debrus, B.; Lebrun, P.; Theunis, L.; Dubois, N.; Decock, L.; Verstraete, A.; Hubert, P.; Charlier, C. Innovative development and validation of an HPLC/DAD method for the qualitative and quantitative determination of major cannabinoids in cannabis plant material. J. Chromatogr. B 2009, 877, 4115-4124. [CrossRef]

4. Flores-Sanchez, I.; Linthorst, H.J.M.; Verpoorte, R. In silico expression analysis of PKS genes isolated from Cannabis sativa L. Genet. Mol. Biol. 2010, 33, 703-713. [CrossRef]

5. Andre, C.M.; Hausman, J.F.; Guerriero, G. Cannabis sativa: The plant of the thousand and one molecules. Plant Sci. 2016, 7, 19. [CrossRef]

6. $\quad$ Fischedick, J.T.; Hazekamp, A.; Erkelens, T.; Choi, Y.H.; Verpoorte, R. Metabolic fingerprinting of Cannabis sativa L., cannabinoids and terpenoids for chemotaxonomic and drug standardization purposes. Phytochemistry 2010, 71, 2058-2073. [CrossRef] [PubMed]

7. Elzinga, S.; Fischedick, J.; Podkolinski, R.; Raber, J.C. Cannabinoids and Terpenes as Chemotaxonomic Markers in Cannabis. Nat. Prod. Chem. Res. 2015, 3, 9.

8. Hurgobin, B.; Tamiru-Oli, M.; Welling, M.T.; Doblin, M.S.; Bacic, A.; Whelan, J.; Lewsey, M.G. Recent advances in Cannabis sativa genomics research. New Phytol. 2021, 230, 73-89. [CrossRef] [PubMed]

9. Raharjo, J.T.; Widjaja, I.; Roytrakul, S.; Verpoorte, R. Comparative Proteomics of Cannabis sativa Plant Tissues. J. Biomol. Tech. 2004, 15, 97-106.

10. Sirikantaramas, S.; Morimoto, S.; Shoyama, Y.; Ishikawa, Y.; Wada, Y.; Shoyama, Y.; Taura, F. The Gene Controlling Marijuana Psychoactivity. J. Biol. Chem. 2004, 279, 39767-39774. [CrossRef] [PubMed]

11. Flores Sanchez, I.J.; Verpoorte, R. Secondary metabolism in cannabis. Phytochem. Rev. 2008, 7, 615-639. [CrossRef]

12. Marks, D.M.; Tian, L.; Wenger, J.P.; Omburo, S.N.; Soto-Fuentes, W.; He, J.; Gang, D.R.; Weiblen, G.D.; Dixon, R.A. Identification of candidate genes affecting D9-tetrahydrocannabinol biosynthesis in Cannabis sativa. J. Exp. Bot. 2009, 60, 3715-3726. [CrossRef] 
13. Van Bakel, H.; Stout, J.M.; Cote, A.G.; Tallon, C.M.; Sharpe, A.G.; Hughes, T.R.; Page, J.E. The draft genome and transcriptome of Cannabis sativa. Genome Biol. 2011, 12, 17. [CrossRef] [PubMed]

14. Livingston, S.J.; Quilichini, T.; Booth, J.K.; Wong, D.C.J.; Rensing, K.H.; Laflamme-Yonkman, J.; Castellarin, S.D.; Bohlmann, J.; Page, J.E.; Samuels, A.L. Cannabis glandular trichomes alter morphology and metabolite content during flower maturation. Plant J. 2019, 101, 37-56. [CrossRef] [PubMed]

15. ElSohly, M.A.; Slade, D. Chemical constituents of marijuana: The complex mixture of natural cannabinoids. Life Sci. 2005, 78, 539-548. [CrossRef] [PubMed]

16. Pacifico, D.; Miselli, F.; Carboni, A. Time course of cannabinoid accumulation and chemotype development during the growth of Cannabis sativa L. Euphytica 2008, 160, 231-240. [CrossRef]

17. Potter, D.J.; Clark, P.; Brown, M.B. Potency of $\Delta 9-$ THC and other cannabinoids in cannabis in England in 2005: Implications for psychoactivity and pharmacology. J. Forensic Sci. 2008, 53, 90-94. [CrossRef] [PubMed]

18. Russo, E.B. Cannabidiol claims and misconceptions. Trends Pharm. Sci. 2017, 38, 198-201. [CrossRef]

19. Small, E.; Marcus, D. A New Crop with New Uses for North America. ASHS 2002, 24, 284-326.

20. Hillig, K.W.; Mahlberg, P.G. A chemotaxonomic analysis of cannabinoid variation in Cannabis (Cannabaceae). Am. J. Bot. 2004, 91, 966-975. [CrossRef]

21. Ren, G.; Zhang, X.; Li, Y.; Ridout, K.; Serrano-Serrano, M.L.; Yang, Y.; Liu, A.; Ravikanth, G.; Nawaz, M.A.; Mumtaz, A.S.; et al. Large-scale whole-genome resequencing unravels the domestication history of Cannabis sativa. Sci. Adv. 2021, 7, 12. [CrossRef] [PubMed]

22. Rustichelli, C.; Ferioli, V.; Baraldi, M.; Zanoli, P.; Gamberini, G. Analysis of cannabinoids in fiber hemp plant varieties (Cannabis sativa L.) by high-performance liquid chromatography. Chromatographia 1998, 47, 215-222. [CrossRef]

23. Mandolino, G.; Bagatta, M.; Carboni, A.; Ranalli, P.; De Meijer, E. Qualitative and quantitative aspects of the inheritance of chemical phenotype in Cannabis. J. Ind. Hemp 2003, 8, 51-57. [CrossRef]

24. Ranalli, P.; Venturi, G. Hemp as a raw material for industrial applications. Euphytica 2004, 140, 1-6. [CrossRef]

25. Salami, S.A.; Martinelli, F.; Giovano, A.; Bachari, A.; Arad, N.; Mantri, N. It is our turn to get cannabis high: Put cannabinoids in food and health baskets. Molecules 2020, 25, 24. [CrossRef] [PubMed]

26. Li, S.Y.; Stuart, J.D.; Li, Y.; Parnas, R.S. The feasibility of converting Cannabis sativa L. oil into biodiesel. Bioresour. Technol. 2010, 101, 8457-8460. [CrossRef]

27. Jikomes, N.; Zoorob, M. The cannabinoid content of legal Cannabis in Washington state varies systematically across testing facilities and popular consumer products. Sci. Rep. 2018, 8, 1-15.

28. Salentijn, E.M.J.; Zhang, Q.; Amaducci, S.; Yang, M.; Trindade, L.M. New developments in fiber hemp (Cannabis sativa L.) breeding. Ind. Crops Prod. 2015, 68, 32-41. [CrossRef]

29. Hillig, K.W. A chemotaxonomic analysis of terpenoid variation in Cannabis. Biochem. Syst. Ecol. 2004, 32, 875-891. [CrossRef]

30. Pacifico, D.; Miselli, F.; Micheler, M.; Carboni, A.; Ranalli, P.; Mandolino, G. Genetics and marker-assisted selection of the chemotype in Cannabis sativa L. Mol. Breed. 2006, 17, 257-268. [CrossRef]

31. Kojoma, M.; Seki, H.; Yoshida, S.; Muranaka, T. DNA polymorphism in the tetrahydrocannabinolic acid (THCA) synthase gene in "drug-type" and "fiber-type" Cannabis sativa L. Forensic Sci. Int. 2006, 159, 132-140. [CrossRef]

32. Piluzza, G.; Delogu, G.; Cabras, A.; Marceddu, S.; Bullitta, S. Differentiation between fiber and drug types of hemp (Cannabis sativa L.) from a collection of wild and domesticated accessions. Genet. Resour. Crop Evol. 2013, 60, 2331-2342. [CrossRef]

33. Grassa, C.J.; Wenger, J.P.; Dabney, C.; Poplawski, S.G.; Motley, S.T.; Michael, T.P.; Schwartz, C.J.; Weiblen, G.D. A complete Cannabis chromosome assembly and adaptive admixture for elevated cannabidiol (CBD) content. New Phytol. 2018, 230, 1665-1679. [CrossRef] [PubMed]

34. Stack, G.M.; Toth, J.A.; Carlson, C.H.; Cala, A.R.; Marrero-González, M.I.; Wilk, R.L.; Gentner, D.R.; Crawford, J.L.; Philippe, G.; Rose, J.K.C.; et al. Season-long characterization of high-cannabinoid hemp (Cannabis sativa L.) reveals variation in cannabinoid accumulation, flowering time, and disease resistance. GCB Bioenergy 2021, 13, 546-561. [CrossRef]

35. Pichini, S.; Mannocchi, G.; Berretta, P.; Zaami, S.; Pirani, F.; Pacifici, R.; Busardo, F.P. $\Delta$ 9-Tetrahydrocannabinol and cnnabidiol time courses in the Sera of "light cannabis" smokers: Discriminating light cannabis use from illegal and medical cannabis use. Ther. Drug Monit. 2020, 42, 151-156. [CrossRef] [PubMed]

36. Zuardi, A.W.; Crippa, J.A.S.; Hallak, J.E.C.; Moreira, F.A.; Guimaraes, F.S. Cannabidiol, a Cannabis sativa constituent, as an antipsychotic drug. Braz. J. Med. Biol. Res. 2006, 39, 421-429. [CrossRef]

37. Velasco, G.; Sánchez, C.; Guzmán, M. Anticancer mechanisms of cannabinoids. Curr. Oncol. 2016, 23, 23-32. [CrossRef] [PubMed]

38. Bachari, A.; Piva, T.J.; Salami, S.A.; Jamshidi, N.; Mantri, N. Roles of cannabinoids in melanoma: Evidence from in vivo studies. Int. J. Mol. Sci. 2020, 21, 6040. [CrossRef] [PubMed]

39. Kojoma, M.; Iida, O.; Makino, Y.; Sekita, S.; Satake, M. DNA fingerprinting of Cannabis sativa using Inter-Simple Sequence Pepeat (ISSR) amplification. Planta Med. 2001, 68, 60-63. [CrossRef]

40. De Meijer, E.P.M.; van der Kamp, H.J.; van Eeuwijk, F.A. Characterisation of Cannabis accessions with regard to cannabinoid content in relation to other plant characters. Euphytica 1992, 62, 187-200. [CrossRef]

41. Marchei, E.; Tittarelli, R.; Pellegrini, M.; Rotolo, M.C.; Pacifici, R.; Pichini, S. Is "light cannabis" really light? Determination of cannabinoids content in commercial products. Clin. Chem. Lab. Med. 2020, 58, 175-177. [CrossRef] 
42. Anwar, F.; Latifa, S.; Ashraf, M. Analytical characterization of hemp (Cannabis sativa) seed oil from different agro-ecological zones of Pakistan. J. Am. Oil Chem. Soc. 2006, 83, 323-329. [CrossRef]

43. Gonçalves, J.; Rosado, T.; Soares, S.; Simão, A.Y.; Caramelo, D.; Luís, Â.; Fernández, N.; Barroso, M.; Gallardo, E.; Duarte, A.P. Cannabis and its secondary metabolites: Their use as therapeutic drugs, toxicological aspects and analytical determination. Medicines 2019, 6, 31. [CrossRef] [PubMed]

44. Leroy, G.; Carroll, E.L.; Bruford, M.W.; DeWoody, J.A.; Strand, A.; Waits, L.; Wang, J. Next-generation metrics for monitoring genetic erosion within populations of conservation concern. Evol. Appl. 2018, 11, 1066-1083. [CrossRef] [PubMed]

45. Danziger, N.; Bernstein, N. Shape Matters: Plant architecture affects chemical uniformity in large-size medical Cannabis plants. Plants 2021, 10, 1834. [CrossRef]

46. Jin, D.; Henry, P.; Shan, J.; Chen, J. Identification of phenotypic characteristics in three chemotype categories in the genus Cannabis. HortScience 2021, 56, 481-490. [CrossRef]

47. Weiblen, G.D.; Wenger, J.P.; Craft, K.J.; ElSohly, M.A.; Mehmedic, Z.; Treiber, E.L.; Marks, M.D. Gene duplication and divergence affecting drug content in Cannabis sativa. New Phytol. 2015, 208, 1241-1250. [CrossRef]

48. Jin, D.; Dai, K.; Xie, Z.; Chen, J. Secondary metabolites profiled in Cannabis inflorescences, leaves, stem barks, and roots for medicinal purposes. Sci. Rep. 2020, 10, 1-14. [CrossRef]

49. Mechtler, K.; Bailer, J.; de Hueber, K. Variations of $\Delta$ 9-THC content in single plants of hemp varieties. Ind. Crop. Prod. 2004, 19, 19-24. [CrossRef]

50. Onofri, C.; de Meijer, E.P.M.; Mandolino, G. Sequence heterogeneity of cannabidiolic- and tetrahydrocannabinolic acid-synthase in Cannabis sativa L. and its relationship with chemical phenotype. Phytochemistry 2015, 116, 57-68. [CrossRef]

51. Lynch, R.C.; Vergara, D.; Tittes, S.; White, K.; Schwartz, C.J.; Gibbs, M.J.; Ruthenburg, T.C.; Decesare, K.; Land, D.P.; Kane, N.C. Genomic and Chemical Diversity in Cannabis. Crit. Rev. Plant Sci. 2016, 35, 349-363. [CrossRef]

52. Zager, J.; Lange, I.; Srividya, N.; Smith, A.; Lange, B.M. Gene networks underlying cannabinoid and terpenoid accumulation in cannabis. Plant Physiol. 2019, 180, 1877-1897. [CrossRef] [PubMed]

53. Blebea, N.M.; Rambu, D.; Costache, T.; Negres, S. Very fast RP-UHPLC-PDA method for identification and quantification of the cannabinoids from hemp oil. Appl. Sci. 2021, 11, 9414. [CrossRef]

54. Mandrioli, M.; Tura, M.; Scotti, S.; Toschi, T.G. Fast Detection of 10 cannabinoids by RP-HPLC-UV method in Cannabis sativa L. Molecules 2019, 24, 2113. [CrossRef] [PubMed]

55. Madej, K.; Chmiołek, A.; Szlachta, K.; Piekoszewski, W. HPLC-DAD analysis of hemp oil supplements for determination of four cannabinoids: Cannabidiol, cannabidiolic acid, cannabinol and delta 9-Tetrahydrocannabinol. Separations 2021, 8, 227. [CrossRef]

56. De Meijer, E.P.M.; Bagatta, M.; Carboni, A.; Crucitti, P.; Moliterni, V.M.C.; Ranalli, P.; Mandolino, G. The inheritance of chemical phenotype in Cannabis sativa L. Genetics 2003, 163, 335-346. [CrossRef]

57. Wenger, J.P.; Dabney, C.J., III; ElSohly, M.A.; Chandra, S.; Radwan, M.M.; Majumdar, C.G.; Weiblen, G.D. Validating a predictive model of cannabinoid inheritance with feral, clinical, and industrial Cannabis sativa. Am. J. Bot. 2020, 107, 1423-1432. [CrossRef]

58. Jin, D.; Henry, P.; Shan, J.; Chen, J. Identification of chemotypic markers in three chemotype categories of Cannabis using secondary metabolites profiled in inflorescences, leaves, stem bark, and roots. Front. Plant Sci. 2021, 12, 699530. [CrossRef]

59. Sawler, J.; Stout, J.; Gardner, K.M.; Hudson, D.; Vidmar, J.; Butler, L.; Page, J.E.; Myles, S. The genetic structure of marijuana and hemp. PLOS ONE 2015, 10, 9. [CrossRef]

60. Soorni, A.; Fatahi, R.; Haak, D.C.; Salami, S.A.; Bombarely, A. Assessment of genetic diversity and population structure in Iranian cannabis germplasm. Sci. Rep. 2017, 7, 10.

61. Bennici, A.; Mannucci, C.; Calapai, F.; Cardia, L.; Ammendolia, I.; Gangemi, S.; Calapai, G.; Soler, D.G. Safety of medical Cannabis in neuropathic chronic pain management. Molecules 2021, 26, 6257. [CrossRef]

62. Hilliard, A.; Stott, C.; Wright, S.; Guy, G.; Pryce, G.; Al-Izki, S.; Bolton, C.; Giovannoni, G. Evaluation of the Effects of Sativex (THC BDS: CBD BDS) on Inhibition of Spasticity in a Chronic Relapsing Experimental Allergic Autoimmune Encephalomyelitis: A Model of Multiple Sclerosis. ISRN Neurol. 2012, 2012, 7. [CrossRef]

63. Brunetti, P.; Lo Faro, A.F.; Pirani, F.; Berretta, P.; Pacifici, R.; Pichini, S.; Busardò, F.P. Pharmacology and legal status of cannabidiol. Ann. Ist. Super Sanita 2020, 56, 285-291.

64. Zuardi, A.W. Cannabidiol: From an inactive cannabinoid to a drug with wide spectrum of action. Bras. J. Psychiatry 2008, 30, 271-280. [CrossRef]

65. Zuardi, A.W.; Crippa, J.A.S.; Hallak, J.E.C.; Pinto, J.P.; Chagas, M.H.N.; Rodrigues, G.G.R.; Dursun, S.M.; Tumas, V. Cannabidiol for the treatment of psychosis in Parkinson's disease. J. Psychopharmacol. 2009, 23, 979-983. [CrossRef]

66. Nagarkatti, P.; Pandey, R.; Rieder, S.A.; Hegde, V.L.; Nagarkatti, M. Cannabinoids as novel anti-inflammatory drugs. Future Med. Chem. 2009, 1, 1333-1349. [CrossRef] [PubMed]

67. Hooshangi Shayesteh, M.R.; Haghi-Aminjan, H.; Baeeri, M.; Rahimifard, M.; Hassani, S.; Gholami, M. Modification of the hemodynamic and molecular features of phosphine, a potent mitochondrial toxicant in the heart, by cannabidiol. Toxicol. Mech. Meth. 2021, 85, 1-14. [CrossRef] [PubMed]

68. Peres, F.F.; Lima, A.C.; Hallak, J.E.C.; Crippa, J.A.; Silva, R.H.; Abílio, V.C. Cannabidiol as a Promising Strategy to Treat and Prevent Movement Disorders. Front. Pharmacol. 2018, 9, 12. [CrossRef]

69. Berman, P.; Futoran, K.; Lewitus, G.M.; Mukha, D.; Benami, M.; Shlomi, T.; Meiri, D. A new ESI-LC/MS approach for comprehensive metabolic profiling of phytocannabinoids in Cannabis. Sci. Rep. 2018, 8, 1-15. [CrossRef] [PubMed] 
70. Pacifici, R.; Marchei, E.; Salvatore, F.; Guandalini, L.; Busardò, F.P.; Pichini, S. Evaluation of cannabinoids concentration and stability in standardized preparations of cannabis tea and cannabis oil by ultra-high performance liquid chromatography tandem mass spectrometry. Clin. Chem. Lab. Med. 2017, 55, 1555-1563. [CrossRef]

71. Pacifici, R.; Marchei, E.; Salvatore, F.; Guandalini, L.; Busardò, F.P.; Pichini, S. Evaluation of long-term stability of cannabinoids in standardized preparations of cannabis flowering tops and cannabis oil by ultra-high-performance liquid chromatography tandem mass spectrometry. Clin. Chem. Lab. Med. 2018, 56, 94-96. [CrossRef] [PubMed]

72. Clarke, R.C. Traditional Cannabis cultivation in Darchula District, Nepal- seed, resin and textiles. J. Ind. Hemp 2007, 12, 19-42. [CrossRef]

73. Mehrani, S.; Azarnivand, H.; Pourtahmasi, K.; Salami, S.A. Comprehensive evaluation of native hemp populations using wood anatomy and stem fiber biometry characteristics towards producing fibers. For. Wood Prod. 2019, 72, $135-145$.

74. Corroon, J.; Kight, R. Regulatory Status of Cannabidiol in the United States: A Perspective. Cannabis Cannabinoid Res. 2018, 3 , 190-194. [CrossRef] [PubMed]

75. Corroon, J.; Phillips, J.A. A Cross-Sectional Study of Cannabidiol Users. Cannabis Cannabinoid Res. 2018, 3, 151-161. [CrossRef] [PubMed]

76. Gutiérrez, A.; del Río, J.C. Chemical characterization of pitch deposits produced in the manufacturing of high-quality paper pulps from hemp fibers. Bioresour. Technol. 2005, 96, 1445-1450. [CrossRef]

77. Guerriero, G.; Hausman, J.F.; Strauss, J.; Ertan, H.; Siddiqui, K.S. Lignocellulosic biomass: Biosynthesis, degradation, and industrial utilization. Eng. Life Sci. 2016, 16, 1-16.

78. Pate, D.W. Possible role of ultraviolet radiation in evolution of Cannabis chemotypes. Econ. Bot. 1983, 37, 396-405. [CrossRef]

79. Bruci, Z.; Papoutsis, I.; Athanaselis, S.; Nikolaou, P.; Pazari, E.; Spiliopoulou, C.; Vyshka, G. First systematic evaluation of the potency of Cannabis sativa plants grown in Albania. Forensic Sci. Int. 2012, 222, 40-46. [CrossRef]

80. Chandra, S.; Lata, H.; Mehmedic, Z.; Khan, I.A.; ElSohly, M.A. Assessment of cannabinoids content in micropropagated plants of Cannabis sativa and their comparison with conventionally propagated plants and mother plant during developmental stages of growth. Planta Med. 2010, 76, 743-750. [CrossRef]

81. Zoller, O.; Rhyn, P.; Zimmerli, B. High-performance liquid chromatographic determination of delta9-tetrahydrocannabinol and the corresponding acid in hemp containing foods with special regard to the fluorescence properties of delta9-tetrahydrocannabinol. J. Chromatogr. A 2000, 872, 101-110. [CrossRef]

82. Kondratovitch, L.; Scotti, A. Recommended Methods for the Identification and Analysis of Cannabis and Cannabis Products; UNODC: Vienna, Austria, 2009; pp. 1-50.

83. Swift, W.; Wong, A.; Li, K.M.; Arnold, J.C.; McGregor, I.S. Analysis of Cannabis Seizures in NSW, Australia: Cannabis Potency and Cannabinoid Profile. PLoS ONE 2013, 8, e70052. [CrossRef]

84. Patel, B.; Wene, D.; Fan, Z. Qualitative and quantitative measurement of cannabinoids in cannabis using modified HPLC/DAD method. J. Pharm. Biomed. Anal. 2017, 146, 15-23. [CrossRef] [PubMed]

85. Jalali, S.; Salami, S.A.; Sharifi, M.; Sohrabi, S. Signaling compounds elicit expression of key genes in cannabinoid pathway and related metabolites in cannabis. Ind. Crops Prod. 2019, 133, 105-110. [CrossRef]

86. Zivovinovic, S.; Alder, R.; Allenspach, M.D.; Steuer, S. Determination of cannabinoids in Cannabis sativa L. samples for recreational, medical, and forensic purposes by reversed-phase liquid chromatography-ultraviolet detection. J. Anal. Sci. Technol. 2018, 9, 10. [CrossRef]

87. Salari, F.; Mansori, H. The effects of jamonate on plastidal terpenoids on Cannabis sativa L. at vegetative stage. Biol. Plant. 2012, 56, 153-156.

88. Gambaro, V.; Dell'Acqua, L.; Farè, F.; Froldi, R.; Saligari, E.; Tassoni, G. Determination of primary active constituents in Cannabis preparations by high-resolution gas chromatography/flame ionization detection and high-performance liquid chromatography/UV detection. Anal. Chim. Acta 2002, 468, 245-254. [CrossRef] 